\title{
Utilization of dental services and associated factors among preschool children in China
}

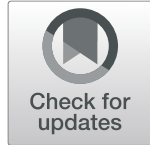

\author{
Xiaoli Gao ${ }^{1 \dagger}$, Min Ding ${ }^{1 \dagger}$, Mengru Xu' ${ }^{1}$, Huijing Wu' ${ }^{1}$, Chunzi Zhang ${ }^{1}$, Xing Wang ${ }^{2}$, Xiping Feng ${ }^{3}$, Baojun Tai ${ }^{4}$, \\ Deyu Hu${ }^{5}$, Huancai Lin ${ }^{6}$, Bo Wang ${ }^{2}$, Shuguo Zheng ${ }^{1}$, Xuenan Liu', Wensheng Rong ${ }^{1}$, Weijian Wang ${ }^{1}$, \\ Chunxiao $\mathrm{Wang}^{7^{*}}$ and $\mathrm{Yan} \mathrm{Si}^{{ }^{*}}$ (D)
}

\begin{abstract}
Background: This study sought to evaluate dental utilization among 3-4-, and 5-year-old children in China and to use Andersen's behavioural model to explore influencing factors, thereby providing a reference for future policy making.

Methods: This study is a cross-sectional study. Data of 40,305 children aged 3-5 years were extracted from the Fourth National Oral Health Survey, which was performed from August 2015 to December 2016. Patient data were collected using a questionnaire, which was answered by the child's parents, and clinical data were collected during a clinical examination. Stratification and survey weighting were incorporated into the complex survey design. Descriptive statistics, bivariate correlations and hierarchical logistic regression results were then analysed to find the factors associated with oral health service utilization.

Results: The oral health service utilization prevalence during the prior 12 months were 9.5\% (95\%Cl: 8.1-11.1\%) among 3-year-old children, $12.1 \%$ (95\%Cl: 10.8-13.5\%) among 4-year-old children, and 17.5\% (95\%Cl: 15.6-19.4\%) among 5year-old children. "No dental diseases" (71.3\%) and "dental disease was not severe" (12.4\%) were the principal reasons why children had not attended a dental visit in the past 12 months. The children whose parents had a bachelor's degree or higher (OR: 2.29,95\%Cl: 1.97-2.67, $p<0.001)$, a better oral health attitude ranging from 5 to $8(\mathrm{OR}: 1.64$, 95\%Cl: 1.43-1.89, $p<0.001$ ), annual per capital income more than 25,000 CNY (OR: 1.40, 95\%Cl: 1.18-1.65, $p<0.001$ ), think their child have worse or bad oral health (OR: 3.54,95\%Cl: $2.84-4.40, p<0.001$ ), and children who often have toothaches (OR: 9.72, 95\%Cl: 7.81-12.09, $p<0.001$ ) were more likely to go to the dentist in the past year.

Conclusion: The prevalence of dental service utilization was relatively low among preschool children. It is necessary to strengthen oral health education for parents and children, thereby improving oral health knowledge as well as attitude, and promoting dental utilization.
\end{abstract}

Keywords: Utilization of dental services, China, Preschool children

\section{Background}

Early childhood caries (ECC) is a widespread public health concern and is defined as the presence of one or more decayed (non-cavitated or cavitated lesions), missing (due to caries) or filled tooth surfaces (dmfs) in any

\footnotetext{
*Correspondence: wangchunxiao0701@163.com; siyanyy@163.com

${ }^{+}$Xiaoli Gao and Min Ding contributed equally to this work.

${ }^{7}$ Center for Chronic and Non-communicable Disease Control and Prevention,

Chinese Center for Disease Control and Prevention, No. 27 Nanwei road, Xicheng district, Beijing 100050, China

'Department of Preventive Dentistry, Peking University School and Hospital of Stomatology, National Engineering Laboratory for Digital and Material Technology of Stomatology, Beijing Key Laboratory of Digital Stomatology, 22 Zhongguancun South Avenue, Haidian District, Beijing 100081, China Full list of author information is available at the end of the article
}

primary (deciduous) tooth in a child aged 6 years or younger [1]. In China, the prevalence of ECC at age 5 ranged from $66.0 \%$ in the Third National Oral Health Epidemiological Survey to $71.9 \%$ in the Fourth National Oral Health Epidemiological Survey [2, 3]. ECC prevalence showed a substantial increasing trend over time, it still remains at a relatively high level. Hence, dental care needs continue to be unmet in our society.

Previous research has found that the mean number of decayed, missing and filled teeth ( $\mathrm{dmft}$ ) among children who had been to a dentist within the previous 12 months was much lower than that in those who had never visited a dentist [4]. It can be concluded that regular

(c) The Author(s). 2020 Open Access This article is distributed under the terms of the Creative Commons Attribution 4.0 International License (http://creativecommons.org/licenses/by/4.0/), which permits unrestricted use, distribution, and reproduction in any medium, provided you give appropriate credit to the original author(s) and the source, provide a link to the Creative Commons license, and indicate if changes were made. The Creative Commons Public Domain Dedication waiver (http://creativecommons.org/publicdomain/zero/1.0/) applies to the data made available in this article, unless otherwise stated. 
check-ups play an important role in preventing the development of ECC. Regular check-ups could diminish treatment costs, ensure a child's healthy growth, and improve oral health-related quality of life [1]. Another study suggested that $94 \%$ of the sample population reported attending regular dental visits after the first visit [5]. The American Academy of Pediatric Dentistry (AAPD) recommends that children attend their first dentist visit upon eruption of the first tooth or no later than 1 year of age [6].

There is no doubt that parental behaviour has an important influence on the good oral health care habits of children. However, a large portion of the general public mistakenly feels that children do not need to see a dentist during the period of primary dentition [7]. In one study in a Hong Kong population, only $44 \%$ of parents sought treatment even though free dental care was offered to their children [8]. Furthermore, oral health service utilization varies from country to country. In a developed country, $41.9 \%$ of American children reported an annual dental visit for general dental care [9]. Moreover, in Belgium, 38 and $79 \%$ of children had utilized dental services at the ages of 3 and 5 years, respectively [10]. For developing country, Brazil, Baldani, et al. find that the pattern of lack of access to dental care has remained unchanged for pre-schoolers over the years [11]. Based on the Third National Oral Health Epidemiological Survey, only 15\% of 5-year-old children have utilized dental services [2]. Therefore, understanding dental visit patterns is important to diminish disparities and inequalities.

Several studies [12] have focused on identifying factors associated with oral health service utilization via theoretical frameworks; one of the most well-known frameworks is Andersen's model. Created in the late 1960s, Andersen's model has become a dynamic and recursive health service model that has been developed in 4 phases [13]. In the initial behaviour model, it was suggested that people's use of health services was dependent on the following: (1) predisposing factors that existed prior to the development of a specific illness, indicating a propensity towards use according to individual characteristics (e.g., age, sex, education); (2) enabling factors that determine the health service resources available and accessible to the individual (e.g., income, insurance coverage); and (3) the need for care, including both self-perceived and clinically evaluated needs. The revised model also recognized that personal health practices, such as diet, exercise, and self-care, interacted with the utilization of health services to influence health outcomes $[13,14]$.

Prior studies using Andersen's behavioural model have shown that oral health services may be influenced by parental education levels, perception of the child's quality, dental insurance and pain [15-17]. Additionally, characteristics such as poor oral health knowledge and poor oral health attitudes are frequently cited as barriers to dental care $[18,19]$. In China, there are few studies on the utilization of oral health services, especially studies involving children. Xu et al. assessed oral health service utilization patterns among preschool children in Beijing, China, and found strong associations between dental pain, available oral health care resources and dental service utilization [20]. In addition, In Chongqing, Wang et al. found that the point of brushing teeth every day and a history of toothache in the past year can also affect the prevalence of oral visits [21]. However, the existing studies have narrowly focused on local areas, and there are few detailed and systematic studies on the influencing factors of oral health care utilization, resulting in crosswise comparisons.

This study was part of the Fourth National Oral Health Epidemiological Survey and aimed to evaluate dental utilization among 3-,4-, and 5-year-old children in China. Andersen's behavioural model was used to investigate influencing factors, thereby providing a reference for future policy making.

\section{Methods}

The Fourth National Oral Health Survey was carried out from August 2015 to December 2016. Data for the 3- to 5 -year-old age groups were extracted; the specific study methodology has been detailed in a previous study [22] A multistage cluster, random, equal proportion sampling method was adopted for this survey.

All 31 provinces, autonomous regions and municipalities, including Tibet in mainland China, were included. Then, the population was stratified into urban and rural residents. We selected two urban and two rural districts randomly from each province using probability proportional to size (PPS) sampling. Next, we used the PPS method to randomly select three streets in urban districts and three townships in rural districts. Last, from each district, three kindergartens were selected by PPS sampling; After their guardians signed the informed consent form, a total of 40,305 children from 372 kindergartens were included in the final analysis. The data collected in this study mainly included an oral health examination and questionnaire survey (see Additional files 1 and 2). Inclusion criteria: 1) Age 3-5 years; 2) Resident time in the local area $>6$ months; 3 ) Informed consent of parents. Exclusion criteria: Not meeting the above conditions.

The clinical data were collected by clinical examination according to the World Health Organization (WHO) methodology and criteria. All participants identified in the survey were examined by trained dentists using disposable dental mirrors and community periodontal index (CPI) probes under artificial light. To 
control for quality, standard assessments of consistency were conducted throughout the survey. All examiners were trained by a standard examiner. All qualified examiners were required to meet the condition that the interexaminer kappa value was greater than 0.8 for the $\mathrm{dmft}$ index. During the survey, duplicate examinations were performed for $5 \%$ of the examinations to ensure consistency, and the kappa value reached 0.95 in the 35-year-old group.

A questionnaire was sent to the children's parents. The questionnaire included questions on the children's background information (i.e., age, sex, urban or rural, region), demographic information (i.e., household income, number of family members, parental education level), oral health knowledge, the attitude of parents, dental pain in the children, the parental evaluation of the health status of their children, and dental attendance experience. The questionnaire was answered by the child's parents, mainly the caregivers in their daily life.

To facilitate statistical analysis, we processed the questions. Data regarding attitude and knowledge were measured by a scoring system. The respondent scored 1 point if he or she showed a positive attitude. When the scores of all eight questions were summed, the total attitude score ranged from 0 to 8 . For the analysis, we regarded a score of $0-4$ points as a negative attitude and $5-8$ points as a positive attitude. Similar to the above method, the respondent received a total score for knowledge-related questions (one point for each correct answer and a total of six questions). The scores from responses to these questions were classified as indicating poor ( $0-3$ points) or good (4-6 points) oral health knowledge. The annual per capita household income was calculated by dividing the total annual household income by the number of households. However, 1362 data points for the number of households and 14,982 data points for the total annual household income were missing. To estimate the parameter more accurately and make full use of the existing data, the expectationmaximization (EM) algorithm was applied to account for the missing values.

The statistical analyses were performed using STATA 14 (Stata Corporation, College Station, TX). Although this survey encompassed a complex sampling, sampling weights were disregarded during the investigation. To reduce sampling error, the samples were post-stratified according to sex, province and urban-rural classification. Survey weights were then computed by comparing the population of each stratum in the sample with the population of that stratum determined in the Sixth Population Census of China [23]. Descriptive analyses were performed to characterize each study variable. Afterwards, chi-square tests and t-tests were used to analyse the association between the independent variables and outcome variables. Statistical significance was set at 0.05 . A hierarchical logistic regression was performed for all variables with significance in the bivariate correlation analyses, and statistical significance was set at 0.05. All reported $p$ values are two-tailed.

\section{Results \\ Descriptive characteristics of the participants}

In the 3- to 5-year-old age group, our final analytic sample consisted of 40,305 participants, among which $17.6 \%$ (95\%CI:16.1-19.3\%) of the children were reported to have utilized oral health services, and 13.1\% (95\%CI: $11.8-14.5 \%$ ) of the children had visited a dentist in the past 12 months. The oral health service utilization in each subgroup was 9.5\% (95\%CI: 8.1-11.1\%) among 3year-old children, $12.1 \%$ (95\%CI: 10.8-13.5\%) among 4year-old children, and $17.5 \%$ (95\%CI: 15.6-19.4\%) among 5 -year-old children in the past 12 months.

Table 1 presents a summary of the descriptive characteristics of the participants. The participants were $50.2 \%$ male. The participants were from east (35.0\%), west (39.3\%) and central (25.8\%) China. Participants from urban and rural areas were approximately equal. Most parents reported positive oral health attitudes (87.7\%) and high levels of knowledge (63.8\%). A total of $68.7 \%$ of parents had a high school education or less, while $31.3 \%$ of parents received a bachelor's degree or higher. Nearly $30.4 \%$ of the participants had an annual per capita income of less than $12,500 \mathrm{CNY}$., $36.9 \%$ of the participants had an annual per capita income between 12,500 CNY and $25,000 \mathrm{CNY}$, and $32.7 \%$ of the participants had an annual per capita income of more than 25,000 CNY. Only $2.5 \%$ of the parents perceived their children's overall health status as "poor"; however, $10.6 \%$ of parents evaluated their children's oral health status as "poor". Most children (70.0\%) reported that they never experienced dental pain. In this study, the prevalence of caries was $63.1 \%$.

\section{Reasons and barriers for visiting a dentist in the past 12 months}

The reasons for the last dental visit among those who visited a dentist in the past 12 months are shown in Fig. 1. In summary, $32.11 \%$ of children aged $3,49.47 \%$ of children aged 4 , and $57.30 \%$ of children aged 5 visited a dentist for treatment, $14.57 \%$ of children aged 3, $11.22 \%$ of children aged 4 , and $9.17 \%$ of children aged 5 visited a dentist for preventive dentalcare, and most of the other children visited only for consultations and check-ups. It can be seen that as age increases, the proportion of "preventive dental care" decreases, whereas the proportion of "receive treatment" increases.

Table 2 shows the barriers to dental visits in the past 12 months. Most participants in the three groups 
Table 1 Descriptive characteristics of the sample of preschool children aged 3-5 years

\begin{tabular}{|c|c|c|c|}
\hline & $\%(95 \% \mathrm{Cl})$ & & $\%(95 \% \mathrm{Cl})$ \\
\hline \multicolumn{4}{|l|}{ Predisposing factor } \\
\hline Age group & & Annual per capital income & \\
\hline 3 & $30.7 \%(30.3-31.2 \%)$ & the lowest to $12,500 \mathrm{CNY}$ & $30.4 \%(30.0-30.9 \%)$ \\
\hline 4 & $34.6 \%(34.2-35.1 \%)$ & $12,5000 \mathrm{CNY}-25,000 \mathrm{CNY}$ & $36.9 \%(36.4-37.3 \%)$ \\
\hline 5 & $34.7 \%(34.2-35.1 \%)$ & $25,000 \mathrm{CNY}$ to the highest & $32.7 \%(32.3-33.2 \%)$ \\
\hline Sex & & Need factor & \\
\hline male & $50.2 \%(49.7-50.7 \%)$ & Toothache & \\
\hline female & $49.8 \%(49.3-50.3 \%)$ & never & $70.0 \%(69.6-70.5 \%)$ \\
\hline \multicolumn{4}{|l|}{ Education } \\
\hline junior high school or lower & $45.3 \%(44.8-45.8 \%)$ & occasionally & $23.2 \%(22.8-23.6 \%)$ \\
\hline senior high school & $23.4 \%(23.0-23.8 \%)$ & often & $2.6 \%(2.4-2.7 \%)$ \\
\hline bachelor's degree or higher & $31.3 \%(30.8-31.7 \%)$ & It's not known & $4.2 \%(4.0-4.4 \%)$ \\
\hline Score of oral health attitude & & Evaluation of overall health & \\
\hline $0-3$ & $12.3 \%(12.0-12.6 \%)$ & good & $30.3 \%(29.8-30.7 \%)$ \\
\hline $4-6$ & $87.7 \%(87.4-88.0 \%)$ & fair & $41.3 \%(40.8-41.8 \%)$ \\
\hline Score of oral health knowledge & & moderate & $26.0 \%(25.5-26.4 \%)$ \\
\hline 0 to 4 & $36.2 \%(35.7-36.6 \%)$ & worse or bad & $2.5 \%(2.3-2.6 \%)$ \\
\hline 5 to 8 & $63.8 \%(63.4-64.3 \%)$ & Evaluation of oral health & \\
\hline Enabling factor & & good & $20.5 \%(20.2-20.9 \%)$ \\
\hline Location & & fair & $35.3 \%(34.8-35.7 \%)$ \\
\hline urban & $50.7 \%(50.2-51.2 \%)$ & moderate & $33.6 \%(33.2-34.1 \%)$ \\
\hline rural & $49.3 \%$ (48.8-49.8\%) & worse or bad & $10.6 \%(10.3-10.9 \%)$ \\
\hline Region & & dmft & \\
\hline west & $39.3 \%(38.8-39.7 \%)$ & $<0$ & $36.9 \%$ (34.3-39.7\%) \\
\hline middle & $25.8 \%$ (25.4-26.2\%) & $>0$ & $63.1 \%(60.3-65.7 \%)$ \\
\hline east & $35.0 \%$ (34.5-35.4\%) & & \\
\hline
\end{tabular}

CNY Chines Yuan

$d m f t$ decayed, missing and filled teeth

reported not visiting a dentist because of "no dental diseases". Approximately $10.0 \%$ of participants cited "dental disease was not severe" as their reason for not obtaining dental care. Only less than $1 \%$ of children did not visit a dentist because of "difficulty of registration".

\section{Factors associated with oral health service utilization in the past 12 months}

Bivariate correlations between dental care utilization and the study variables are summarized in Table 3 . We examined the factors influencing the use of dental health services among the three age groups. The predisposing factor variables, such as education, knowledge, and attitude were significantly related to the children's utilization of oral health services. The enabling variables, including annual per capita income and rural-urban locations, had a significant association with the frequency of dental care. The need variables, such as dental pain, evaluated dental health, and dmft scores (mean:3.42, SD:
4.220) were also significantly associated with dental visits, reflecting dental need.

Table 4 shows the results of the multivariable logistic regression. In terms of predisposing factors, parents with higher educational levels (OR: 2.29, 95\%CI: 1.97-2.67, $p<0.001$ ) were more likely to take their children to the dentist than those who had a junior high school or lower education. Abundant oral health knowledge (OR: 1.38, 95\%CI: $1.24-1.53, p<0.001)$ and positive oral health attitudes (OR: 1.64, 95\%CI: 1.43-1.89, $p<0.001$ ) were associated with a higher probability of visiting the dentist at least once. Regarding enabling factors, children who lived in rural areas were less likely to have visited a dentist in the past 12 months. Children from families who had a high annual per capita income (OR: 1.40, 95\% CI: $1.18-1.65, p<0.001)$ had higher probability of dental visits. With regard to need factors, parents who thought their children's oral status was "worsening or bad" or considered their children's overall health as "good" 


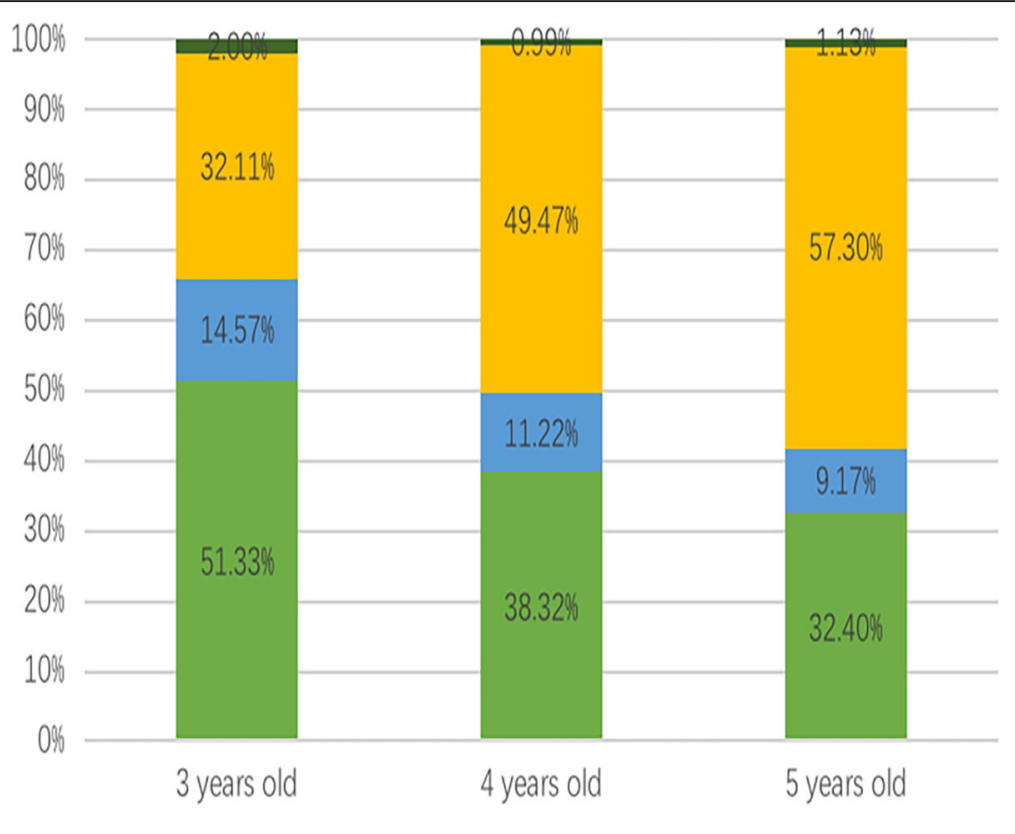

a consulting and check-up apreventive dentalcare receiving treatment aunknown

Fig. 1 The percentage of the reasons for the last dental visit in the past 12 months

tended to take their children to the dentist. Higher $\mathrm{dmft}$ (OR: $1.05,95 \%$ CI: 1.04-1.07, $p<0.001$ ) scores were associated with the use of dental care services. In addition, children who had reported a toothache (OR: 9.72, 95\%CI: 7.81-12.09, $p<0.001$ ) were more likely to visit a dentist than those that had never reported a toothache.

\section{Discussion}

The oral health service utilization prevalence in the past 12 months was $9.5 \%$ among 3 -year-old children, $12.1 \%$ among 4-year-old children, and $17.5 \%$ among 5-year-old children. Compared with the Third National Oral Health Survey, among 5-year-old children, the prevalence of utilization of dental care increased slightly, but there is still a gap between utilization in China and the level of dental health care utilization in developed countries. In our study, we aimed to explain the patterns of dental service utilization among 3- to 5-year-old children in China with Andersen's behavioural model. We find that education, knowledge, attitude, dental pain, evaluated dental health, and $\mathrm{dmft}$ scores are associated with oral health utilization, and annual per capita income and

Table 2 Reasons for not visiting a dentist in the past 12 months

\begin{tabular}{|c|c|c|c|c|}
\hline Reasons & 3 year old $(\%)$ & 4 year old(\%) & 5 year old(\%) & $3-5$ year old $(\%$ \\
\hline No dental diseases & $76.80 \%$ & $71.00 \%$ & $66.10 \%$ & $71.30 \%$ \\
\hline Dental disease was not severe & $10.00 \%$ & $12.40 \%$ & $14.80 \%$ & $12.40 \%$ \\
\hline No need to cure primary teeth & $8.00 \%$ & $8.90 \%$ & $12.90 \%$ & $9.90 \%$ \\
\hline Economic issue & $1.10 \%$ & $1.10 \%$ & $1.30 \%$ & $1.20 \%$ \\
\hline Inconvenience & $1.80 \%$ & $1.90 \%$ & $2.00 \%$ & $1.90 \%$ \\
\hline No time & $4.90 \%$ & $5.50 \%$ & $5.80 \%$ & $5.40 \%$ \\
\hline Fear of pain & $3.40 \%$ & $4.10 \%$ & $4.20 \%$ & $3.90 \%$ \\
\hline No dentists nearby & $1.60 \%$ & $1.90 \%$ & $1.80 \%$ & $1.80 \%$ \\
\hline Fear of infectious diseases & $0.90 \%$ & $1.50 \%$ & $0.90 \%$ & $1.10 \%$ \\
\hline No reliable dentists & $2.10 \%$ & $2.50 \%$ & $2.30 \%$ & $2.30 \%$ \\
\hline Difficulty of registration & $0.50 \%$ & $0.50 \%$ & $0.60 \%$ & $0.50 \%$ \\
\hline Seeing dentists in kindergarten & $3.00 \%$ & $4.00 \%$ & $4.70 \%$ & $3.90 \%$ \\
\hline Other reasons & $7.10 \%$ & $7.20 \%$ & $7.00 \%$ & $7.10 \%$ \\
\hline
\end{tabular}


Table 3 Bivariate comparisons of oral health service utilization in the past 12 months

\begin{tabular}{|c|c|c|c|c|c|c|c|c|}
\hline \multirow[t]{2}{*}{ Predisposing factor } & \multicolumn{2}{|l|}{3 years old } & \multicolumn{2}{|l|}{4 years old } & \multicolumn{2}{|l|}{5 years old } & \multicolumn{2}{|l|}{$3-5$ years old } \\
\hline & $\%(95 \% \mathrm{Cl})$ & $\mathrm{P}$ & $\%(95 \% \mathrm{Cl})$ & $P$ & $\%(95 \% \mathrm{Cl})$ & $P$ & $\%(95 \% \mathrm{Cl})$ & $\mathrm{P}$ \\
\hline Sex & & $=0.197$ & & $=0.432$ & & $=0.207$ & & $=0.696$ \\
\hline male & $9.9 \%(8.2-11.9 \%)$ & & $11.9 \%(10.4-13.5 \%)$ & & $17.1 \%(15.3-19.0 \%)$ & & $13.0 \%(11.7-14.6 \%)$ & \\
\hline female & $9.0 \%(7.7-10.5 \%)$ & & $12.4 \%(11.1-13.8 \%)$ & & $17.9 \%(16.0-20.1 \%)$ & & $13.2 \%(11.9-14.6 \%)$ & \\
\hline Education & & $<0.001$ & & $<0.001$ & & $<0.001$ & & $<0.001$ \\
\hline junior high school or lower & $5.3 \%(4.2-6.6 \%)$ & & $8.8 \%(7.6-10.2 \%)$ & & $12.3 \%(10.7-14.0 \%)$ & & $9.0 \%(8.0-10.1 \%)$ & \\
\hline senior high school & $9.5 \%(8.0-11.1 \%)$ & & $12.2 \%(10.6-13.9 \%)$ & & $18.4 \%(16.2-20.9 \%)$ & & $13.5 \%(12.1-15.0 \%)$ & \\
\hline bachelor's degree or higher & $16.4 \%(14.3-18.9 \%)$ & & $18.8 \%(16.3-21.6 \%)$ & & $27.9 \%(25.3-30.8 \%)$ & & $20.9 \%(19.0-22.9 \%)$ & \\
\hline Score of oral health attitude & & $<0.001$ & & $<0.001$ & & $<0.001$ & & $<0.001$ \\
\hline 0 to 3 & $3.7 \%(2.7-5.1 \%)$ & & $5.5 \%(4.4-7.0 \%)$ & & $9.5 \%(7.9-11.4 \%)$ & & $6.5 \%(5.5-7.6 \%)$ & \\
\hline 4 to 6 & $10.3 \%(8.8-12.0 \%)$ & & $13.0 \%(11.6-14.5 \%)$ & & $18.7 \%(16.9-20.7 \%)$ & & $14.1 \%(12.8-15.5 \%)$ & \\
\hline Score of oral health knowledge & & $<0.001$ & & $<0.001$ & & $P<0.001$ & & $P<0.001$ \\
\hline 0 to 4 & $6.1 \%(5.2-7.2 \%)$ & & $8.7 \%(7.4-10.3 \%)$ & & $12.3 \%(10.8-13.9 \%)$ & & $9.2 \%(8.3-10.3 \%)$ & \\
\hline 4 to 8 & $11.3 \%(9.5-13.4 \%)$ & & $14.1 \%(12.6-15.7 \%)$ & & $20.8 \%(18.8-23.0 \%)$ & & $15.4 \%(13.9-17.1 \%)$ & \\
\hline \multicolumn{9}{|c|}{ Enabling factor } \\
\hline Location & & $<0.000$ & & $<0.000$ & & $<0.000$ & & $<0.000$ \\
\hline urban & $13.1 \%(10.8-15.9 \%)$ & & $15.4 \%(13.1-18.1 \%)$ & & $22.7 \%(19.8-25.9 \%)$ & & $17.2 \%(14.9-19.8 \%)$ & \\
\hline rural & $6.9 \%(5.4-8.9 \%)$ & & $9.8 \%(8.4-11.4 \%)$ & & $13.7 \%$ (11.8-15.8\%) & & $10.2 \%(8.9-11.7 \%)$ & \\
\hline Region & & $=0.283$ & & $=0.023$ & & $=0.003$ & & $=0.011$ \\
\hline east & $9.3 \%(6.7-12.8 \%)$ & & $10.2 \%(8.4-12.0 \%)$ & & $14.5 \%(12.1-17.3 \%)$ & & $11.4 \%(9.4-13.8 \%)$ & \\
\hline middle & $8.1 \%(6.2-10.5 \%)$ & & $11.1 \%(8.8-13.8 \%)$ & & $15.5 \%(12.6-18.8 \%)$ & & $11.6 \%(9.7-13.8 \%)$ & \\
\hline west & $11.0 \%(8.5-14.2 \%)$ & & $14.5 \%(12.1-17.3 \%)$ & & $21.5 \%(18.1-25.3 \%)$ & & $15.9 \%(13.3-18.8 \%)$ & \\
\hline Annual per capital income & & $<0.001$ & & $<0.001$ & & $<0.001$ & & $<0.001$ \\
\hline the lowest to $12,500 \mathrm{CNY}$ & $6.0 \%(4.5-7.8 \%)$ & & $8.8 \%(7.1-10.8 \%)$ & & $13.1 \%(11.2-15.3 \%)$ & & $9.4 \%(8.1-11.0 \%)$ & \\
\hline $12,5000 \mathrm{CNY}-25,000 \mathrm{CNY}$ & $10.4 \%(8.7-12.3 \%)$ & & $12.7 \%(11.4-14.2 \%)$ & & $17.5 \%(15.5-19.6 \%)$ & & $13.6 \%(12.2-15.1 \%)$ & \\
\hline $25,000 \mathrm{CNY}$ to the highest & $12.8 \%(11.1-14.7 \%)$ & & $15.7 \%(13.4-18.2 \%)$ & & $23.3 \%(20.5-26.3 \%)$ & & $17.4 \%(15.6-19.3 \%)$ & \\
\hline \multicolumn{9}{|c|}{ Need factor } \\
\hline Toothache & & $<0.001$ & & $<0.001$ & & $<0.001$ & & $<0.001$ \\
\hline never & $6.0 \%(4.8-7.5 \%)$ & & $6.0 \%(5.0-7.1 \%)$ & & $7.2 \%(6.1-8.4 \%)$ & & $6.3 \%(5.4-7.4 \%)$ & \\
\hline occasionally & $26.9 \%(23.3-30.9 \%)$ & & $29.5 \%(26.4-32.8 \%)$ & & $33.7 \%(30.4-37.2 \%)$ & & $30.9 \%(28.4-33.6 \%)$ & \\
\hline often & $37.7 \%$ (30.4-45.6\%) & & $50.4 \%(43.2-57.5 \%)$ & & $58.5 \%$ (51.7-65.0\%) & & $52.7 \%(47.6-57.7 \%)$ & \\
\hline its not known & $5.1 \%(3.3-8.0 \%)$ & & $6.9 \%(4.7-10.2 \%)$ & & $10.9 \%(75.8-15.5 \%)$ & & $7.5 \%(5.7-9.9 \%)$ & \\
\hline Evaluation of overall health & & $=0.004$ & & $=0.692$ & & $=0.038$ & & $=0.030$ \\
\hline good & $9.6 \%(7.8-11.8 \%)$ & & $12.1 \%(10.4-14.0 \%)$ & & $17.0 \%(15.0-19.3 \%)$ & & $13.1 \%(11.6-14.7 \%)$ & \\
\hline fair & $10.2 \%(8.7-11.9 \%)$ & & $12.6 \%(10.9-14.5 \%)$ & & $19.0 \%(16.6-21.7 \%)$ & & $13.9 \%(12.4-15.6 \%)$ & \\
\hline moderate & $8.7 \%(7.0-10.7 \%)$ & & $11.6 \%(10.1-13.2 \%)$ & & $15.6 \%(13.5-18.0 \%)$ & & $12.1 \%(10.8-13.5 \%)$ & \\
\hline worse or bad & $4.9 \%(2.7-8.7 \%)$ & & $10.8 \%(7.1-16.3 \%)$ & & $19.5 \%(14.1-26.4 \%)$ & & $12.2 \%(9.5-15.6 \%)$ & \\
\hline Evaluation of oral health & & $<0.001$ & & $<0.001$ & & $<0.001$ & & $<0.001$ \\
\hline good & $5.3 \%(4.0-7.0 \%)$ & & $4.5 \%(3.5-5.8 \%)$ & & $6.6 \%(5.1-8.4 \%)$ & & $5.4 \%(4.5-6.6 \%)$ & \\
\hline fair & $6.7 \%(5.4-8.4 \%)$ & & $8.1 \%(6.9-9.5 \%)$ & & $10.3 \%(8.6-12.3 \%)$ & & $8.3 \%(7.2-9.6 \%)$ & \\
\hline moderate & $10.1 \%(8.3-12.4 \%)$ & & $13.8 \%(11.8-15.9 \%)$ & & $20.2 \%(17.9-22.8 \%)$ & & $15.1 \%(13.4-16.9 \%)$ & \\
\hline worse or bad & $31.2 \%(26.6-36.2 \%)$ & & $34.6 \%$ (31.2-38.3\%) & & $42.8 \%(39.5-46.2 \%)$ & & $37.2 \%(34.4-40.2 \%)$ & \\
\hline $\mathrm{dmft}$ & & $<0.001$ & & $<0.001$ & & $<0.001$ & & $<0.001$ \\
\hline
\end{tabular}

$P$ values are based on chi-square test 
rural-urban location can also affect the use of dental service.

Among the predisposing characteristics, demographic factors suggested the possibility of needing health services. In the current study, we found that age had a significant effect on dental care utilization. Oral health service utilization during the past 12 months showed a rising trend with age. This finding could possibly be explained by the cumulative effect of increasing oral problems as children grow [24]. The teeth of older children are exposed to environmental conditions for a longer period of time, which increases the likelihood of dental disease $[24,25]$. According to the Fourth National Oral Epidemiology Report [3], the prevalence of dental caries in deciduous teeth increases with age between 3 and 5 years of age. Another explanation is that older children are able to more clearly convey their pain or discomfort to parents and dentists and can better cooperate during dental procedures [20].

For preschool children, parental characteristics play an important role in the utilization of health services. In this study, nearly half of the parents had no more than a junior high school education; regarding reasons for not visiting dentists, approximately $70 \%$ of parents believed that their children did not have any dental diseases. This unrealistic optimism may stem from the absence of health knowledge. Oral pain is often mistakenly regarded as the only symptom of perceived disease [26]. Prior studies have also mentioned that in China, traditional Chinese medicine considers the oral cavity to be part of the entire body; therefore, the first treatment modality for dental disease is sometimes home remedies rather than professional treatment [7].

Our results confirmed that family income demonstrated a positive relationship with dental health service utilization. The susceptibility to caries and dental pain is socio-economically and geographically unequal [27]. Children who are disadvantaged by poverty have an increased burden of disease but attend few dental visits [28]. Regarding medical insurance, the reimbursement prevalence for oral diseases is notably low in China [29], and the public must pay out of pocket for clinical treatment. The low-income population is focused on meeting basic needs and is less likely to seek dental care [30]. Furthermore, a prior study confirmed that poverty associated with education leads to reduced knowledge and a poor attitude regarding oral health [31]. Thus, financial barriers have a negative effect on dental care; similar results have been reported in prior studies [32-35].

The results of this study showed that children who lived in urban areas were more likely to receive dental services than those who lived in rural areas. This phenomenon may have occurred because health systemrelated economic resources are not dispersed homogeneously throughout the country [14]. A shortage in the dental workforce, particularly paediatric dentists, is a common health care issue in low-income areas [36]. The density of pediatric dentists at county (city) level is significantly related to the utilization of oral health care at county (city) level [37]. A similar finding was reported in America, where utilization of dental care showed a negative trend as urbanization decreased [38].

According to Andersen's behavioural model, perceived illness or the probability of its occurrence was a main reason for seeking dental services. Results from the multiple regression analysis in the present study showed that pain was the strongest factor associated with oral health service utilization. According to prior studies, dental pain, which can lead to difficulty in eating and consequently result in malnutrition and underweight, has become the most important reason for dental treatment $[25,39]$. Besides that, our study also showed that parents' perception of their children's dental health was an important predictor of a child's use of oral health care services. Parents who evaluated their child's dental status as "poor" took their child to the dentist more often than those who evaluated their child's status as "good". An explanation for the result might be parents' beliefs about seeking curative but preventive services [40]. Thus, the utilization patterns of oral health services among preschool children in China are still disease-oriented, and effective methods for promoting preventive dental care need to be expanded. However, parents who considered their child's overall health to be poor were less likely to bring their child to an oral hospital; this is possibly because whole body health is more urgent than oral health, and thus oral health becomes a secondary concern.

In the present study, the dmft was associated with oral health service utilization. Another study confirms the results [41]. The prevalence of dental caries based on clinical examination was $63.1 \%$, however, only $17.6 \%$ of children were reported to have utilized oral health services. This difference suggests that dental need did not translate into demand. A prior study indicated that potential demand is caused by both demanders and suppliers [42]. Due to parents' lack of awareness or incorrect awareness of oral health, there is no effective demand for treatment of unrecognized diseases. Furthermore, disadvantages associated with medical institutions providing inappropriate services, such as high cost, difficult registration, and long waiting time, among others, are also important factors that affect patients' visits. A study has shown that oral hygiene service utilization increases slightly, when a child is diagnosed with an oral problem [43]. To achieve the goal of continuously and effectively transforming objective need into subjective demand, the countermeasures that are adopted must be aimed at changing behaviour on both the supply and 
Table 4 Logistic regression model of oral health service utilization in the past 12 months

\begin{tabular}{|c|c|c|c|c|c|c|}
\hline & \multicolumn{2}{|l|}{ Model 1} & \multicolumn{2}{|l|}{ Model 2} & \multicolumn{2}{|l|}{ Model 3} \\
\hline & OR $(95 \% \mathrm{Cl})$ & $P$ & OR $(95 \% \mathrm{Cl})$ & P & OR $(95 \% \mathrm{Cl})$ & P \\
\hline \multicolumn{7}{|l|}{ Predisposing factor } \\
\hline \multicolumn{7}{|l|}{ Age } \\
\hline 3 & 1 (reference) & & 1 (reference) & & 1 (reference) & \\
\hline 4 & $1.38(1.17-1.62)$ & $<0.001$ & $1.37(1.16-1.62)$ & $<0.001$ & $1.06(0.89-1.26)$ & 0.50 \\
\hline 5 & $2.19(1.91-2.52)$ & $<0.001$ & $2.18(1.89-2.50)$ & $<0.001$ & $1.33(1.15-1.53)$ & $<0.001$ \\
\hline \multicolumn{7}{|l|}{ Education } \\
\hline junior high school or lower & 1 (reference) & & 1 (reference) & & 1 (reference) & \\
\hline senior high school & $1.44(1.27-1.63)$ & $<0.001$ & $1.31(1.15-1.48)$ & $<0.001$ & $1.33(1.15-1.54)$ & $<0.001$ \\
\hline bachelor's degree or higher & $2.39(2.09-2.75)$ & $<0.001$ & $1.99(1.75-2.26)$ & $<0.001$ & $2.29(1.97-2.67)$ & $<0.001$ \\
\hline \multicolumn{7}{|l|}{ Score of oral health attitude } \\
\hline 0 to 3 & 1 (reference) & & 1 (reference) & & 1 (reference) & \\
\hline 4 to 6 & $1.71(1.47-1.98)$ & $<0.001$ & $1.66(1.43-1.92)$ & $<0.001$ & $1.64(1.43-1.89)$ & $<0.001$ \\
\hline \multicolumn{7}{|l|}{ Score of oral health knowledge } \\
\hline 0 to 4 & 1 (reference) & & 1 (reference) & & 1 (reference) & \\
\hline 5 to 8 & $1.36(1.24-1.51)$ & $<0.001$ & $1.33(1.21-1.46)$ & $<0.001$ & $1.38(1.24-1.53)$ & $<0.001$ \\
\hline \multicolumn{7}{|l|}{ Enabling factor } \\
\hline \multicolumn{7}{|l|}{ Location } \\
\hline urban & & & 1 (reference) & & 1 (reference) & \\
\hline rural & & & $0.73(0.61-0.88)$ & 0.00 & $0.61(0.50-0.75)$ & $<0.001$ \\
\hline \multicolumn{7}{|l|}{ Region } \\
\hline west & & & 1 (reference) & & / & / \\
\hline middle & & & $0.92(0.72-1.18)$ & 0.51 & / & / \\
\hline east & & & $1.17(0.93-1.47)$ & 0.17 & / & / \\
\hline \multicolumn{7}{|l|}{ Annual per capital income } \\
\hline the lowest to $12500 \mathrm{CNY}$ & & & 1 (reference) & & 1 (reference) & \\
\hline $12500 \mathrm{CNY}-25000 \mathrm{CNY}$ & & & $1.15(1.00-1.33)$ & 0.05 & $1.22(1.05-1.42)$ & 0.01 \\
\hline $25000 \mathrm{CNY}$ to the highest & & & $1.28(1.08-1.51)$ & 0.00 & $1.40(1.18-1.65)$ & $<0.001$ \\
\hline \multicolumn{7}{|l|}{ Need factor } \\
\hline \multicolumn{7}{|l|}{ Toothache } \\
\hline never & & & & & 1 (reference) & \\
\hline occasionally & & & & & $4.49(3.99-5.05)$ & $<0.001$ \\
\hline often & & & & & $9.72(7.81-12.09)$ & $<0.001$ \\
\hline its not known & & & & & $1.22(0.92-1.61)$ & 0.17 \\
\hline \multicolumn{7}{|l|}{ Evaluation of overall health } \\
\hline good & & & & & 1 (reference) & \\
\hline fair & & & & & $0.81(0.72-0.92)$ & 0.00 \\
\hline moderate & & & & & $0.65(0.57-0.74)$ & $<0.001$ \\
\hline worse or bad & & & & & $0.56(0.42-0.75)$ & $<0.001$ \\
\hline \multicolumn{7}{|l|}{ Evaluation of oral health } \\
\hline good & & & & & 1 (reference) & \\
\hline fair & & & & & $1.31(1.11-1.54)$ & 0.00 \\
\hline moderate & & & & & $1.97(1.64-2.37)$ & $<0.001$ \\
\hline worse or bad & & & & & $3.54(2.84-4.40)$ & $<0.001$ \\
\hline $\mathrm{dmft}$ & & & & & $1.05(1.04-1.07)$ & $<0.001$ \\
\hline
\end{tabular}


demand sides. For example, oral examinations may be carried out in school or in the community, and when a child is found to have dental caries, timely treatment may be given.

When calculating the survey weights, data of the 35 -year-old age group in the Sixth Population Census of China were not available, so we selected the data from 1 to 4-year-old age group as a substitute, which may have affected the accuracy of the results. In addition, per capita household income was obtained by filling in missing values. Although accurate data were utilized to the greatest extent possible, this data substitution may have resulted in deviations to some extent. Furthermore, the present study had some limitations. First, the children in the sample were all from kindergartens, and children not attending kindergartens in remote areas were not included, resulting in selection bias. Second, because the studied factors occurred in the past, recall bias was unavoidable. Third, the questionnaire was completed by the parents, and its accuracy was subject to the parents' understanding of their children. Fourth, our study is of crosssectional design, which excludes any inference about causality, A future longitudinal study is highly desirable to address these limitations.

Despite the above limitations, this study was still a comprehensive and systematic reflection of the current utilization of health services by preschool children in China. To improve the oral health of pre-schoolers in China, the study findings have some implications for policy adjustment to increase the utilization of oral health services. First, it is time for the government to pay attention to the inequality in the distribution of dental resources and take measures to solve this problem. Second, expansion of insurance coverage for dental treatments would be beneficial for children who are less able to afford oral health services. Third, promoting parents' awareness of oral health would increase the prevalence of dental service utilization.

\section{Conclusion}

The present study illustrated that the prevalence of dental service utilization was still relatively low among preschool children. Based on Andersen's behavioural model, predisposing, enabling, and needs variables as well as oral health practices were associated with increased dental health services utilization. In addition, disparities in oral health care utilization remain and need to be addressed by the joint efforts of the government and the whole society.

\section{Supplementary information}

Supplementary information accompanies this paper at https://doi.org/10. 1186/s12903-019-0996-x.
Additional file 1: Oral health assessment form for children.

Additional file 2: Oral health questionnaire for parents/caregivers.

\section{Abbreviations}

AAPD: American Academy of Pediatric Dentistry; CPI: Community periodontal index; dmfs: Decayed (non-cavitated or cavitated lesions), missing (due to caries) or filled tooth surfaces; dmft: Decayed, missing and filled teeth; ECC: Early childhood caries; PPS: Probability proportional to size; WHO: World Health Organization

\section{Acknowledgements}

I would like to express my sincere gratitude to those who worked for the Fourth National Oral Health Survey and the study participants, including the children, parents or caregivers, and kindergarten teachers.

\section{Authors' contributions}

YS conceived of the procedure for the research; XG, MD, MX, HW, and CZ analysed study data; XW, XF, BT, DH, HL, BW, SZ, XL, WR, WW, CW, and YS provided significant instruction regarding the Fourth National Oral Health Survey; XG wrote the manuscript; and YS revised the draft. All authors read and approved the final manuscript.

\section{Funding}

Our study was supported by Scientific Research Fund of National Health Commission of the People's Republic of China (201502002), which provided economic support for our study in its previous research design and data collection

\section{Availability of data and materials}

The datasets used during the current study are available from the corresponding author on reasonable request.

\section{Ethics approval and consent to participate}

This study protocol was approved by the Stomatological Ethics Committee of the Chinese Stomatological Association, Beijing (No. 2014-003). A written informed consent form was sent to the parents of each child to explain the content of the survey. Each parent returned a signed. informed consent form.

Consent for publication

Not applicable.

\section{Competing interests}

The authors declare that they have no competing interests.

\section{Author details}

${ }^{1}$ Department of Preventive Dentistry, Peking University School and Hospital of Stomatology, National Engineering Laboratory for Digital and Material Technology of Stomatology, Beijing Key Laboratory of Digital Stomatology, 22 Zhongguancun South Avenue, Haidian District, Beijing 100081, China.

${ }^{2}$ Peking University School and Hospital of Stomatology, National Engineering Laboratory for Digital and Material Technology of Stomatology, Beijing Key Laboratory of Digital Stomatology, Chinese Stomatological Association, Beijing, China. ${ }^{3}$ Department of Preventive Dentistry, Shanghai Ninth People's Hospital, Shanghai Jiao Tong University School of Medicine, Shanghai, China. ${ }^{4}$ Department of Preventive Dentistry, State Key Laboratory Breeding Base of Basic Science of Stomatology (Hubei-MOST) and Key Laboratory of Oral Biomedicine Ministry of Education, School and Hospital of Stomatology, Wuhan University, Wuhan, China. ${ }^{5}$ Department of Preventive Dentistry, West China School of Stomatology, Sichuan University, Chengdu, China.

${ }^{6}$ Department of Preventive Dentistry, Guanghua School of Stomatology, Hospital of Stomatology, Sun Yat-sen University and Guangdong Provincial Key Laboratory of Stomatology, Guangzhou, China. ${ }^{7}$ Center for Chronic and Non-communicable Disease Control and Prevention, Chinese Center for Disease Control and Prevention, No. 27 Nanwei road, Xicheng district, Beijing 100050, China. 
Received: 24 August 2019 Accepted: 24 December 2019

Published online: 08 January 2020

\section{References}

1. Dentistry AAOP, Pediatrics AAO. Policy on early childhood caries (ECC): classifications, consequences, and preventive strategies. Pediatr Dent. 2011; 30(7 Suppl):31-3.

2. Qi XQ. Report of the third national oral health survey. Beijing: People's Medical Publishing House; 2008.

3. Wang X. Report of the forth national oral health survey. Beijing: People's Medical Publishing House; 2018.

4. Pakpour A, Hidarnia A, Hajizadeh E, Kumar S, Harrison A. The status of dental caries and related factors in a sample of Iranian adolescents. Med Oral Patol Oral Cir Bucal. 2011;16(6):822-7.

5. Hoeft KS, Barker JC, Masterson EE. Maternal beliefs and motivations for first dental visit by low-income Mexican-American children in California. Pediat Dent. 2011;33(5):392.

6. Stewart DCL, Ortega AN, Alos V, Martin B, Dowshen SA, Katz SH. Utilization of dental services and preventive oral health behaviors among preschoolaged children from Delaware. Pediatr Dent. 1999;21(7):403.

7. Wei SHY. Dental caries prevalence and related factors in 5-year-old children in Hong Kong. Pediatr Dent. 1993;15(2):116.

8. Hilton IV, Stephen S, Barker JC, Weintraub JA. Cultural factors and children's oral health care: a qualitative study of carers of young children. Community Dent Oral Epidemiol. 2007;35(6):429-38.

9. Berdahl T, Hudson J, Simpson L, McCormick MC. Annual report on Children's health care: dental and orthodontic utilization and expenditures for children, 2010-2012. Acad Pediatr. 2016;16(4):314-26.

10. Leroy R, Bogaerts K, Hoppenbrouwers K, Martens LC, Declerck D. Dental attendance in preschool children - a prospective study. Int J Paediatr Dent. 2013:23(2):84-93.

11. Baldani MH, Rocha JS, Fadel CB, Nascimento AC, Antunes JLF, Moyses SJ. Assessing the role of appropriate primary health care on the use of dental services by Brazilian low-income preschool children. Cad Saude Publica. 2017;33(11):e00158116.

12. David G, Andersen RM, Chen M. A public health model of the dental care process. Med Care Rev. 1989;46(4):439-96.

13. Andersen RM. Revisiting the behavioral model and access to medical care: does it matter? J Health Soc Behav. 1995:36(1):1-10.

14. Andersen R, NEWMAN JF. Societal and individual determinants of medical care utilization in the United States. Milbank Q. 2010;83(4):95-124.

15. Lin M, Sappenfield W, Hernandez L. Child- and state-level characteristics associated with preventive dental care access among U.S. children 5-17 years of age. Matern Child Health J. 2012;16(2):320-9.

16. Goettems ML, Ardenghi TM, Demarco FF, Romano AR, Torriani DD. Children's use of dental services: influence of maternal dental anxiety, attendance pattern, and perception of children's quality of life. Community Dent Oral Epidemiol. 2012:40(5):451-8.

17. Piovesan C, Antunes JLF, Guedes RS, Ardenghi TM. Influence of selfperceived oral health and socioeconomic predictors on the utilization of dental care services by schoolchildren. Braz Oral Res. 2011;25(2):143.

18. Shahrabani S, Benzion U, Machnes Y, Gal A. The use of dental services for children: implications of the 2010 dental reform in Israel. Health Policy. 2015;119(2):117-26.

19. Baldani MH, De Lara API, Antunes JLF. Inequalities in dental services utilization among Brazilian low-income children: the role of individual determinants. J Public Health Dent. 2011;71(1):46-53.

20. Xu M, Yuan C, Sun X, Cheng M, Xie Y, Si Y. Oral health service utilization patterns among preschool children in Beijing, China. BMC Oral Health. 2018; 18(1):31.

21. Wang JX, Yang ZY, Wu XY, Cai T, Deng L, Lu XY, Ding XB, Zhou Z. An investigation on the need, the utilization, and the influencing factors of dental services for pre-school children in selected areas in Chongqing province. Hua Xi Kou Qiang Yi Xue Za Zhi. 2019;37(2):187-92.

22. Lu HX, Tao DY, Lo ECM, Li R, Wang X, Tai BJ, et al. The 4th National Oral Health Survey in the Mainland of China: Background and Methodology. Chin J Dent Res. 2018;21(3):161-5.

23. HU Y. Application of post-stratification method in data analysis of population sampling survey. Popul Res. 1997;21(6):51-4.

24. Machry RV, Tuchtenhagen S, Agostini BA, Teixeira CRDS, Piovesan C, Mendes FM, et al. Socioeconomic and psychosocial predictors of dental healthcare use among Brazilian preschool children. BMC Oral Health. 2013; 13(1):60.

25. Villalobos-Rodelo JJ, Medina-Solis CE, Maupome G, Lamadrid-Figueroa H, Casanova-Rosado AJ, Casanova-Rosado JF, et al. Dental needs and socioeconomic status associated with utilization of dental services in the presence of dental pain: a case-control study in children. J Orofac Pain. 2010;24(3):279-86

26. Amin MS, Perez A, Nyachhyon P. Barriers to utilization of dental services for children among low-income families in Alberta. J Can Dent Assoc. 2014;80: e51.

27. Barasuol JC, Garcia LP, Freitas RC, Dalpian DM, Menezes JVNB, Santos BZ. Dental care utilization among children in Brazil: an exploratory study based on data from national household surveys. Cien Saude Colet. 2019;24(2):64957.

28. Edelstein BL. Disparities in Oral health and access to care: findings of National Surveys. Ambul Pediatr. 2002;2(2):141-7.

29. Qu X, Wang M, Shi WY, Zhou DX. Analysis of the development of dental insurance in China. Hua Xi Kou Qiang Yi Xue Za Zhi. 2011;29(1):106-10.

30. Badri P, Wolfe R, Farmer A, Amin M. Psychosocial determinants of adherence to preventive dental attendance for preschool children among Filipino immigrants in Edmonton, Alberta. J Immigr Minor Health. 2018; 20(3):658-67.

31. Medina Solís CE. Factors influencing the use of dental health services by preschool children in Mexico. Pediatr Dent. 2006;28(3):285-92.

32. Darmawikarta D, Chen Y, Carsley S, Birken CS, Parkin PC, Schroth RJ, et al. Factors associated with dental care utilization in early childhood. Pediatrics. 2014;133(6):e1594

33. Granvillegarcia AF, Clementino MA, Gomes MC, Costa EM, Pintosarmento TC, Paiva SM. Influence of Oral problems and biopsychosocial factors on the utilization of dental services by preschool children. J Dent Child (Chic). 2015; 82(2):76-83.

34. Chaiana P, Machado AT, Medeiros MF, Antonio AB, Edgard M. Individual and contextual factors influencing dental health care utilization by preschool children: a multilevel analysis. Braz Oral Res. 2017;31:e27.

35. Ardenghi TM, Vargas-Ferreira F, Piovesan C, Mendes FM. Age of first dental visit and predictors for Oral healthcare utilisation in preschool children. Oral Health Prev Dent. 2012;10(1):17-27.

36. Martin AB, Vyavaharkar M, Veschusio C, Kirby H. Rural-urban differences in dental service utilization among an early childhood population enrolled in South Carolina Medicaid. Matern Child Health J. 2012;16(1):203-11.

37. Heidenreich JF, Kim AS, Scott JM, Chi DL. Pediatric dentist density and preventive care utilization for Medicaid children. Pediatr Dent. 2015;37(4): $371-5$.

38. Mckernan SC, Kuthy RA, Hanley PF, Jones MP, Momany ET, Mcquistan MR, Damiano PC. Geographic variation of dental utilization among low income children. Health Place. 2015:34:150-6.

39. Moura-Leite FR, Ramos-Jorge ML, Bonanato K, Paiva SM, Vale MP, Pordeus $\mid A$, et al. Prevalence, intensity and impact of dental pain in 5-year-old preschool children. Oral Health Prev Dent. 2008;6(4):295-301.

40. Medinasolis CE, Maupomé G, Del Socorro HM, Péreznúñez R, Avilaburgos L, Lamadridfigueroa $\mathrm{H}$. Dental health services utilization and associated factors in children 6 to 12 years old in a low-income country. J Public Health Dent. 2010;68(1):39-45.

41. Qiu RM, Tao Y, Zhou Y, Zhi QH, Lin HC. The relationship between children's oral health-related behaviors and their caregiver's social support. BMC Oral Health. 2016;16(1):86.

42. Wang Z, Wang $H$, Caifang $C$, et al. An analysis on need and demand for dental service in urban residents of Beijing. Zhonghua Kou Qiang Yi Xue Za Zhi. 2000;35(6):476-8.

43. Sanjeevan V, Janakiram C, Joseph J. Effectiveness of school-based dental screening in increasing dental care utilization: a systematic review and meta-analysis. Indian J Dent Res. 2019;30(1):117-24.

\section{Publisher's Note}

Springer Nature remains neutral with regard to jurisdictional claims in published maps and institutional affiliations. 